revista docência do ensino

\title{
SEÇÃO: ARTIGOS
}

\section{Aprendizagem à luz da Andragogia: comparação da percepção de discentes entre cursos de Ciências Contálbeis}

\author{
Kelly Renata Mariani Kozievitch ${ }^{1}$, Lucas Précoma Lorenzini², \\ Moacir Borges da Silva ${ }^{3}$, Silvana Anita Walter ${ }^{4}$
}

\section{RESUMO}

Este estudo analisou a percepção discente quanto ao processo de aprendizagem no curso de Ciências Contábeis, sob os fundamentos da Andragogia no modelo de Knowles, Holton e Swanson (2011), de forma comparativa entre duas instituições de ensino superior, com aplicação de uma pesquisa survey para 148 estudantes. No instrumento de coleta de dados, foram utilizadas as escalas de concordância baixa, moderada e alta, por meio do teste-t. Os resultados evidenciaram que os alunos possuem alta compreensão da necessidade de aprender, se consideram independentes e responsáveis pelo processo de aprendizagem, apresentam baixa e moderada concordância quanto à programação dos próprios estudos, necessitam de suporte de terceiros para aprender e aceitam novas metodologias. Conclui-se que os alunos estão no processo de assimilação dos fundamentos andragógicos ao identificarem a aprendizagem como experiência prazerosa, a sua utilidade para resolver situações diárias e o compromisso com seus próprios estudos.

Palavras-chave: Andragogia. Aprendizagem. Ciências Contábeis.

\section{Como citar este documento - ABNT}

KOZIEVITCH, Kelly Renata Mariani; LORENZINI, Lucas Précoma;

SILVA, Moacir Borges da; WALTER, Silvana Anita. Aprendizagem à luz da Andragogia: comparação da percepção de discentes entre cursos de Ciências Contábeis. Revista Docência do Ensino Superior, Belo Horizonte, v. 11, e024343, p. 1-20, 2021. DOI: https://doi.org/10.35699/22375864.2021.24343.
Recebido em: 04/08/2020 Aprovado em: 29/10/2020 Publicado em: 11/03/2021

\footnotetext{
${ }^{1}$ Universidade do Oeste do Paraná (Unioeste), Cascavel, PR, Brasil. ORCID ID: https://orcid.org./0000-0002-4691-1243. E-mail: kellyrenata@udc.edu.br 2 Universidade do Oeste do Paraná (Unioeste), Cascavel, PR, Brasil. ORCID ID: https://orcid.org/0000-0002-8155-056X. E-mail: Iplorenzini@gmail.com

${ }^{3}$ Universidade do Oeste do Paraná (Unioeste), Cascavel, PR, Brasil. ORCID ID: https://orcid.org/0000-0002-6440-5600. E-mail: moacirbs62@gmail.com

${ }^{4}$ Universidade do Oeste do Paraná (Unioeste), Cascavel, PR, Brasil.

ORCID ID: https://orcid.org/0000-0003-1684-5465. E-mail: silvanaanita.walter@gmail.com
} 


\section{Aprender a la luz de la Andragogía: comparación de la percepción de estudiantes entre carreras de Contabilidad}

\section{RESUMEN}

Este estudio analizó la percepción del estudiante del proceso de aprendizaje en el curso de Contabilidad, bajo los fundamentos de Andragogía en el modelo de Knowles, Holton y Swanson (2011) de manera comparativa entre dos instituciones de educación superior, con la aplicación de una busca survey para 148 estudiantes. En el instrumento de recolección de datos se utilizaron las escalas de concordancia baja, moderada y alta, utilizando el teste-t. Los resultados mostraron que los estudiantes tienen una alta compresión de la necesidad de aprender, se consideran independientes y responsables del proceso de aprendizaje, tienen un acuerdo bajo y moderado con respecto a la programación de sus estudios, necesitan el apoyo de otras personas para aprender y aceptan nuevas metodologías. Se concluye que los estudiantes se encuentran en proceso de asimilación de fundamentos andragógicos al identificar los motivos del aprendizaje como una experiencia agradable, la utilidad del aprendizaje para resolver situaciones cotidianas, y el compromiso con su propio aprendizaje.

Palabras clave: Andragogía. Aprendizaje. Contabilidad.

\section{Learning in the light of Andragogy: comparation of student perception among Accounting courses}

\section{ABSTRACT}

This study analyzed the student perception regarding the learning process in the academic educational environment of the Accounting course, under the Andragogy proposed by Knowles, Holton and Swanson (2011), comparing two higher education institutions, with a survey that has been applied for 148 students. In the data collection instrument, the scales of low, moderate and high agreement were used, through $t$-test. The results showed that the respondents of both institutions have a high understanding of the necessity to learn, consider themselves independent and responsible for the learning process, presented low and moderate agreement as planning their own studies and that they need other people's support to learn and they accept new teaching methodologies. It is concluded that students are in the process of assimilating andragogical fundamentals when they identify learning as a pleasant experience, its utility to solve daily situations and commitment to their own studies.

Keywords: Andragogy. Learning. Accounting. 


\section{INTRODUÇÃO}

O ensino é o processo no qual o sujeito se forma graças ao conjunto de ações, significados e atuações sociais deliberadamente organizadas de tal maneira que o processo remete à ação do professor. Eboli (2005) afirma que a concepção de ensino se fundamenta no planejamento e na promoção de situações em que o aluno pode organizar suas experiências, estruturar suas ideias, analisar seus processos e expressar seus pensamentos.

A aprendizagem dos alunos é afetada pelas mudanças metodológicas e pelas tecnologias do mundo moderno, quando incorporada a uma forma de trabalho ou de pensamento. Conforme Schlochauer e Leme (2012), a escola adquire novos papéis, pois possibilita o gosto e o prazer em aprender, transmite ao estudante o que a humanidade já sabe sobre si mesma e sobre a natureza, incentivando a visão crítica, a curiosidade e o questionamento constante.

A educação de adultos é tema presente nas pesquisas na área do Ensino, evidenciando que a busca por resultados satisfatórios depende da aplicação de técnicas específicas que podem ser exploradas nos modelos andragógicos para transmissão de conhecimento aos alunos que escolhem o que e quanto querem aprender (BELLAN, 2005).

A Andragogia pode ser conceituada como a arte e a ciência de ajudar os adultos a aprender, num processo em que todos deveriam se controlar em um exercício livre, de vontade própria, do autoconceito e do confronto de si com a realidade, a partir do qual emergem a orientação e a motivação para aprender longe da abordagem tradicional, na qual há controle externo dos alunos e comportamentos pré-estabelecidos pela instituição de ensino e pelo professor (KNOWLES, 1980; KNOWLES; HOLTON; SWANSON, 2011).

O modelo teórico da Andragogia desenvolvido por Knowles, Holton e Swanson (2011) é estruturado em três dimensões: a) objetivos e propósitos para o aprendizado; b) diferenças individuais face ao contexto no momento da escolha da estratégia de aprendizagem e; c) os princípios andragógicos, que compreendem a necessidade do saber do aprendiz, o autoconceito, a experiência prévia, a prontidão para aprender, a orientação para a aprendizagem e a motivação.

O caminho da Andragogia e sua relação com o ensino superior foi objeto do estudo de Romanzi e Vidi (2017), que discutiram sobre dois métodos nessa etapa educacional: a Andragogia (condução do adulto a partir de suas experiências) e a Heutagogia (condução individual no ato de aprender), a fim de identificar qual possibilita a melhor formação. Ao final, concluíram que o planejamento deve contemplar a multiplicidade da realidade profissional, ressalvando que a adesão aos princípios andragógicos está relacionada diretamente à maneira como professor e discente interagem. 
Silva e Torres (2017) analisaram as contribuições das recentes pesquisas no Brasil sobre a Andragogia, com a finalidade de descrever como essa ciência tem sido praticada no nível de treinamento profissional nas diferentes áreas de atuação, observando quais procedimentos pedagógicos podem ser adaptados, aproveitados ou modificados para melhoria e facilitação da aprendizagem. Após tal análise, evidenciou-se que a produção científica sobre Andragogia em língua portuguesa ainda é insuficiente.

Carvalho (2017) apresentou a teoria andragógica e a sua importância na prática docente universitária através de pesquisa bibliográfica e concluiu que a apropriação dos conhecimentos dessa teoria possibilita ao professor universitário ter uma prática docente adaptada às necessidades de aprendizagem dos estudantes adultos, de acordo com suas experiências, aptidões e interesses.

Na pesquisa de Godoi e Ferreira (2016), foi realizado um estudo de caso fundamentado na Andragogia utilizando a metodologia ativa com aplicação do Peer Instruction (estratégia de ensino criada para ajudar a tornar as aulas mais interativas e fazer com que os estudantes fiquem intelectualmente envolvidos com o que está acontecendo em sala de aula) em uma instituição de ensino superior (IES). Os resultados demonstraram que a metodologia emerge como uma possível estratégia de ensino e aprendizagem para os cursos de graduação em Administração.

As possibilidades e os desafios para uma abordagem andragógica no ensino em Administração e Contabilidade constituíram o tema do estudo de Franco, Paiva e Helmold (2015), que descreveu e analisou a concordância dos estudantes desses cursos em relação aos pressupostos da Andragogia e da pedagogia tradicional e à percepção sobre qual dessas formas se manifesta mais proeminentemente na instituição que estudam. As considerações finais indicaram que, embora os alunos apresentem concordância maior com os pressupostos da Andragogia, o ensino que vivenciam ainda apresenta características da pedagogia tradicional.

Schmdt et al. (2012) analisaram o perfil dos alunos do curso de Ciências Contábeis de instituições de ensino do Sul do Brasil, evidenciaram que a maioria dos alunos está satisfeita com a opção pelo curso, que a profissão se apresenta como promissora, que é possível obter uma boa remuneração com ela e que a escolha pelo curso pode gerar desenvolvimento pessoal, permitindo-lhes contribuir para mudar a sociedade.

A iniciativa do aluno é fundamental no processo de aprendizagem, e a percepção dos discentes no ensino da Contabilidade também foi objeto de estudo desenvolvido por Costa et al. (2018), destacando problemas quanto aos aspectos de envolvimento e dedicação dos 
alunos ao estudo, ressaltando ainda a sua relutância em assumir responsabilidades e realizar esforços, sinalizando necessidade do aprimoramento da educação contábil.

Por outro lado, os acadêmicos têm demonstrado preocupação, conforme demonstraram Costa et al. (2018), na evidenciação de que têm conhecimento da responsabilidade individual pelo próprio aprendizado e a vêem como uma das habilidades mais aprimoradas.

Para analisar a percepção dos alunos quanto às técnicas utilizadas na transmissão do conhecimento, Brandão, Cavalcante e Temoteo (2014) estudaram o processo de aprendizagem de alunos do curso de graduação de Turismo e de Hotelaria sob a perspectiva andragógica, utilizando o modelo de Knowles, Holton e Swanson (2011), e notaram que estudantes possuem características como autonomia, autodirecionamento e apresentam níveis de independência quando em processo de formação e de desenvolvimento de competências. Tais dados revelam a necessidade de repensar o processo de formação profissional para melhor aproveitar essas características.

Para alunos adultos que buscam na universidade o conhecimento e o preparo profissional, a aprendizagem exige compromisso e técnicas de ensino que sejam atrativas e estejam relacionadas às suas experiências ou, ainda, às suas expectativas quanto às rotinas da profissão escolhida. Nesse sentido, o estudo proposto buscou responder o seguinte questionamento: Qual é a percepção dos alunos do curso de Ciências Contábeis de uma IES pública e de uma IES privada quanto ao processo de aprendizagem de adultos?

Diante disso, tem-se como objetivo analisar a percepção discente quanto ao processo de aprendizagem no ambiente acadêmico do curso de Ciências Contábeis, sob os fundamentos da Andragogia no modelo proposto por Knowles, Holton e Swanson (2011) de forma comparativa entre duas instituições de ensino superior.

\section{DESENVOLVIMENTO}

\section{Materiais e métodos}

Para realização deste estudo, foram observadas duas etapas: a primeira, destinada à revisão da literatura e a segunda, destinada ao levantamento dos dados com alunos do curso de graduação de Ciências Contábeis em duas Instituições de Ensino Superior, sendo uma instituição pública e uma instituição privada.

A população alvo foram os acadêmicos inscritos nos cursos de Ciências Contábeis. O censo foi composto de 148 discentes respondentes, sendo 74 alunos de cada IES, dos 2으, 3으 e 4음 anos. 
Os alunos foram selecionados de forma aleatória, considerando os presentes em sala de aula e com concordância na participação da pesquisa. A aplicação dos questionários foi efetuada no mês de março de 2019.

Para definir as categorias vinculadas aos princípios da Andragogia, foi utilizado o modelo andragógico de Knowles, Holton e Swanson (2011). Replicou-se em parte este estudo, com a inclusão do estudo comparativo entre os dois grupos pesquisados, por meio de método estatístico teste-t para evidenciar a diferença de médias. Desta forma, de acordo com o modelo, as categorias referiam-se aos princípios da Andragogia, e as subcategorias elaboradas para explorar o entendimento de cada princípio são: a) necessidade de saber do aprendiz; b) conceito de si; c) experiência prévia; d) prontidão para aprender; e) orientação para a aprendizagem; e f) motivação para aprender (BRANDÃO; CAVALCANTE; TEMOTEO, 2014).

O questionário apresentado aos discentes abordou 32 questões separadas em dois blocos. 0 primeiro bloco consistiu em 7 questões referentes aos dados demográficos dos respondentes: idade, sexo, período ou ano em que está matriculado, se já concluiu outra graduação, se já fez ou faz estágio na área contábil, se já trabalha nesse campo, com o que trabalha e se a IES em que está matriculado é pública ou privada. O segundo bloco é composto por 25 questões relativas à percepção dos discentes no processo de aprendizagem nos princípios andragógicos. Nesse bloco, foi utilizada uma escala de 5 pontos, com a variação " 1 " a " 5 ", em que: " 5 " e " 4 " refere-se à concordância alta do discente; " 3 " à concordância moderada; e " 2 " e "1" à baixa concordância.

Os dados foram tabulados em planilha eletrônica. A confiabilidade do questionário foi verificada por meio de Alpha de Cronbach, o nível de concordância ou discordância dos respondentes em análise simples de frequência para cada grupo, seguida da análise comparativa de médias pelo teste-t utilizando-se do software SPSS versão 21.

\section{Resultados e discussões}

A análise dos dados dividiu-se em sete seções. Na primeira delas, foi identificado o perfil dos acadêmicos respondentes da pesquisa; na segunda, a confiabilidade do questionário por meio de teste estatístico Alpha de Cronbach; na terceira, o princípio da Andragogia referente à necessidade de aprender dos respondentes; na quarta, o conceito de si; na quinta, o princípio referente à prontidão para aprender; na sexta, a orientação para aprendizagem; e, por fim, na sétima, as motivações do acadêmico para aprender. 
Aprendizagem à luz da Andragogia: comparação da percepção de discentes entre cursos de Ciências Contábeis

Kelly Renata Mariani Kozievitch, Lucas Précoma Lorenzini, Moacir Borges da Silva, Silvana Anita Walter

\section{Perfil dos acadêmicos respondentes}

Para avaliar o perfil dos discentes respondentes, constatou-se a participação de 74 discentes do curso de Ciências Contábeis da IES pública e de 75 discentes da IES privada, tendo sido excluído um discente que entregou o instrumento de pesquisa incompleto, distribuída por período e ano equivalente, conforme Tabela 1:

\begin{tabular}{l|c|c|c|c}
\hline \multicolumn{1}{c|}{ Período } & \multicolumn{2}{c|}{ IES Pública } & \multicolumn{2}{c}{ IES Privada } \\
\hline 20 Ano & 26 & $(35,14 \%)$ & 30 & $(40,54 \%)$ \\
\hline 3ㅇ Ano & 24 & $(32,43 \%)$ & 34 & $(45,95 \%)$ \\
\hline 4ㅇ Ano & 24 & $(32,43 \%)$ & 10 & $(13,51 \%)$ \\
\hline Total & 74 & $(100 \%)$ & 74 & $(100 \%)$ \\
\hline
\end{tabular}

Tabela 1 - Frequência dos respondentes por período de estudo Fonte: Dados da pesquisa (2019).

Para melhor conhecer os respondentes, foram questionados idade, sexo, se já possuía outra graduação, se atuava na área contábil e se fez/faz ou não estágio na área. A Tabela 2 evidencia esses resultados separados por IES.

\begin{tabular}{l|c|c|c|c|c}
\hline \multicolumn{2}{|c|}{ Dados } & \multicolumn{2}{c|}{ IES Pública } & \multicolumn{2}{c}{ IES Privada } \\
\hline Idade & Entre 18 e 22 anos & 56 & $(75,7 \%)$ & 40 & $(54,1 \%)$ \\
\hline & Acima de 22 anos & 18 & $(24,3 \%)$ & 34 & $(45,9 \%)$ \\
\hline Sexo & Masculino & 35 & $(47,3 \%)$ & 42 & $(56,8 \%)$ \\
\hline \multirow{2}{*}{$\begin{array}{l}\text { Outra } \\
\text { Graduação }\end{array}$} & Feminino & 39 & $(52,7 \%)$ & 32 & $(43,2 \%)$ \\
\cline { 2 - 6 } $\begin{array}{l}\text { Atuação na } \\
\text { área }\end{array}$ & Sim & 9 & $(12,2 \%)$ & 6 & $(8,1 \%)$ \\
\cline { 2 - 6 } & Não & 65 & $(87,8 \%)$ & 68 & $(98,9 \%)$ \\
\hline Estágio & Namo & 38 & $(51,4 \%)$ & 29 & $(39,2 \%)$ \\
\cline { 2 - 6 } na área & Sim & 36 & $(48,3 \%)$ & 45 & $(60,8 \%)$ \\
\cline { 2 - 6 } & Não & 41 & $(44,6 \%)$ & 22 & $(29,7 \%)$ \\
\hline
\end{tabular}

Tabela 2 - Frequência dos respondentes (sexo, idade, outra graduação e atuação na área) Fonte: Dados da pesquisa (2019).

Nas informações relativas à idade dos estudantes do curso de Ciências Contábeis que participaram da pesquisa, observa-se que as duas instituições de educação possuem a maioria de alunos mais jovens matriculados, considerando que 56 acadêmicos da IES Pública e 40 acadêmicos da IES Privada têm entre 18 e 22 anos.

\section{Confiabilidade do Questionário}

Após a identificação dos respondentes, foi realizada a verificação da confiabilidade do questionário aplicado com utilização da ferramenta estatística Alpha de Cronbach, utilizado 
Aprendizagem à luz da Andragogia: comparação da percepção de discentes entre cursos de Ciências Contábeis

Kelly Renata Mariani Kozievitch, Lucas Précoma Lorenzini, Moacir Borges da Silva, Silvana Anita Walter

para medir a consistência interna de uma escala, ou seja, para avaliar a magnitude em que os itens de um instrumento estão correlacionados (CORTINA, 1993).

\begin{tabular}{l|c|c}
\hline \multicolumn{1}{c|}{ Dimensões } & № de Variáveis & Alpha de Cronbach \\
\hline (A) Necessidade de Aprender & 5 & 0,767 \\
\hline (B) O conceito de si & 8 & 0,834 \\
\hline (C) Experiência prévia & 3 & 0,345 \\
\hline (D) Prontidão para aprender & 2 & 0,657 \\
\hline (E)Orientação para aprendizagem & 3 & 0,869 \\
\hline (F) Motivação para aprender & 4 & 0,763 \\
\hline
\end{tabular}

Tabela 3 - Alpha de Cronbach por constructo Fonte: Dados da pesquisa (2019).

De acordo com Hair Jr. et al. (2007), para que um fator apresente consistência interna satisfatória, este deve possuir Alpha de Cronbach superior a 0,60. No caso dos 6 constructos apresentados, apenas a experiência prévia do aprendiz não obteve confiabilidade mesmo excluindo uma variável, sendo, então, retirada das análises.

\section{Necessidade de Aprender}

Na Andragogia, a necessidade de aprender deve partir do discente, e o docente tem como atividade ajudá-lo a conscientizar-se da necessidade de aprender e auxiliá-lo a dar significado para uma aprendizagem efetiva. Rogers e Freiberg (1969) reforçam essa ideia e relatam que a aprendizagem é significativa quando o aluno percebe a relevância do que será aprendido. Ao responder as questões, o respondente deveria classificar as variáveis em Concordância Baixa (CB), Concordância Moderada (CM) e Concordância Alta (CA).

\begin{tabular}{l|c|c|c|c|c|c}
\hline \multicolumn{1}{c|}{ Variáveis } & \multicolumn{3}{c|}{ IES Pública } & \multicolumn{3}{c}{ IES Privada } \\
\cline { 2 - 8 } & CB & CM & CA & CB & CM & CA \\
\hline Consciência do que necessita aprender. & 2 & 20 & 52 & 2 & 18 & 53 \\
\hline Relevância do que é ensinado para sua vida pessoal. & 6 & 22 & 46 & 5 & $\underline{\mathbf{2 8}}$ & 41 \\
\hline $\begin{array}{l}\text { Relevância do que é ensinado para sua vida } \\
\text { profissional. }\end{array}$ & 1 & 6 & 67 & 5 & 9 & 60 \\
\hline $\begin{array}{l}\text { Compreensão de como a aprendizagem é conduzida. } \\
\text { Liberdade de escolha e decisão de fazer ou não o }\end{array}$ & 6 & $\underline{\mathbf{3 1}}$ & 37 & 3 & 21 & 50 \\
\hline \begin{tabular}{l} 
curso. \\
\hline
\end{tabular} & 7 & 15 & 52 & 5 & 17 & 52 \\
\hline
\end{tabular}

Tabela 4 - Necessidade de Aprender

Fonte: Dados da pesquisa (2019).

Evidenciou-se na pesquisa que os alunos da IES pública e da IES privada possuem, na maioria, concordância alta da necessidade de aprender, destacando os dados relativos à compreensão de como a aprendizagem é conduzida. Por outro lado, observou-se que 31 respondentes da 
IES pública concordaram de forma moderada quanto à compreensão de como a aprendizagem é conduzida. Já na IES privada, 28 responderam que concordam de forma moderada quanto à relevância do que é ensinado para sua vida pessoal.

\begin{tabular}{|c|c|c|c|c|c|}
\hline Variáveis & IES & Média & $\begin{array}{l}\text { Desvio } \\
\text { Padrão }\end{array}$ & $\begin{array}{l}p \text {-valor } \\
\text { Levene }\end{array}$ & $\begin{array}{l}p \text {-valor } \\
\text { teste-t }\end{array}$ \\
\hline \multirow{2}{*}{ Consciência do que necessita aprender. } & Pública & 4,05 & 0,87 & \multirow[t]{2}{*}{0,25} & \multirow{2}{*}{0,73} \\
\hline & Privada & 4,11 & 1,02 & & \\
\hline \multirow{2}{*}{$\begin{array}{l}\text { Relevância do que é ensinado para sua } \\
\text { vida pessoal. }\end{array}$} & Pública & 3,70 & 0,93 & \multirow[t]{2}{*}{0,54} & \multirow[t]{2}{*}{0,93} \\
\hline & Privada & 3,72 & 0,94 & & \\
\hline \multirow{2}{*}{$\begin{array}{l}\text { Relevância do que é ensinado para sua } \\
\text { vida profissional. }\end{array}$} & Pública & 4,49 & 0,71 & \multirow[t]{2}{*}{0,03} & \multirow[t]{2}{*}{0,10} \\
\hline & Privada & 4,26 & 0,97 & & \\
\hline \multirow{2}{*}{$\begin{array}{l}\text { Compreensão de como a aprendizagem é } \\
\text { conduzida. }\end{array}$} & Pública & 3,61 & 0,89 & \multirow[t]{2}{*}{0,06} & \multirow[t]{2}{*}{0,10} \\
\hline & Privada & 3,84 & 0,79 & & \\
\hline \multirow{2}{*}{$\begin{array}{l}\text { Liberdade de escolha e decisão de fazer } \\
\text { ou não o curso. }\end{array}$} & Pública & 4,04 & 1,05 & \multirow[t]{2}{*}{0,40} & \multirow[t]{2}{*}{0,31} \\
\hline & Privada & 4,22 & 1,06 & & \\
\hline
\end{tabular}

Tabela 5 - Teste-t para amostras independentes - necessidade de aprender Fonte: Dados da pesquisa (2019).

Como pode ser observado na tabela 5, não existe diferença significativa entre as médias das duas instituições. Logo, é possível afirmar que não há distinção sobre a necessidade de aprender nos alunos de IES pública e privada. Como menor média entre as variáveis, tem-se a "Compreensão de como a aprendizagem é conduzida" na universidade pública, o que evidencia a compreensão do acadêmico de como a aprendizagem é conduzida. Embora seja a menor, ainda possui $72,20 \%$ da média máxima que poderia alcançar, denotando ainda uma boa compreensão do acadêmico.

\section{O conceito de si do aprendiz (acadêmico)}

Essa categoria de análise buscou identificar a independência do discente, sua iniciativa, autonomia, responsabilidade e capacidade de evoluir por si próprio. Knowles (1980) enfatiza que, na infância, o aluno é moldado em uma estrutura pedagógica de dependência do professor, pois é o docente quem determina as regras e o que deve e como deve ser estudado. Ao chegar na educação adulta, a metodologia é outra. No entanto, o aluno ainda busca essa dependência. 
Aprendizagem à luz da Andragogia: comparação da percepção de discentes entre cursos de Ciências Contábeis

Kelly Renata Mariani Kozievitch, Lucas Précoma Lorenzini, Moacir Borges da Silva, Silvana Anita Walter

\begin{tabular}{l|c|c|c|c|c|c}
\hline \multirow{2}{*}{ Variáveis } & \multicolumn{3}{c|}{ IES Pública } & \multicolumn{3}{c}{ IES Privada } \\
\cline { 2 - 9 } & CB & CM & CA & CB & CM & CA \\
\hline $\begin{array}{l}\text { Espera da determinação do que aprender e como } \\
\text { aprender }\end{array}$ & 2 & 33 & $\mathbf{3 9}$ & 4 & 24 & $\underline{\mathbf{4 6}}$ \\
\hline Iniciativa no processo de aprendizagem. & 13 & 37 & $\mathbf{2 4}$ & 4 & 22 & $\mathbf{4 8}$ \\
\hline Capacidade de evoluir e agir de maneira autônoma & 13 & 20 & 41 & 5 & 14 & 54 \\
\hline Independência no processo de aprendizagem. & 12 & 28 & $\underline{\mathbf{3 4}}$ & 5 & 23 & $\underline{\mathbf{4 6}}$ \\
\hline Responsabilidade pela própria aprendizagem. & 8 & 23 & $\underline{\mathbf{4 3}}$ & 4 & 16 & $\underline{\mathbf{5 4}}$ \\
\hline Programação dos próprios estudos. & $\underline{\mathbf{2 6}}$ & $\underline{\mathbf{2 1}}$ & $\mathbf{2 7}$ & $\mathbf{1 0}$ & $\mathbf{3 3}$ & 31 \\
\hline Habilidade para solucionar os problemas existentes & & & & & & \\
no seu processo de aprendizagem. & $\underline{\mathbf{1 3}}$ & $\underline{\mathbf{2 8}}$ & 33 & $\underline{\mathbf{9}}$ & $\underline{\mathbf{2 4}}$ & 41 \\
\hline Comprometimento com a própria aprendizagem. & $\mathbf{9}$ & $\mathbf{2 2}$ & 43 & $\mathbf{8}$ & 19 & 46 \\
\hline
\end{tabular}

Tabela 6 - O conceito de si do aprendiz acadêmico Fonte: Dados da pesquisa (2019).

No quesito independência no processo de aprendizagem, nota-se uma dependência do discente na espera da determinação do que aprender e em como aprender. Essa é maior na IES privada, com aproximadamente $62 \%$ contra $52 \%$ na IES pública. Todavia, ainda em sua maioria, esses mesmos acadêmicos consideram-se independentes e responsáveis por seu processo de aprendizagem.

\begin{tabular}{|c|c|c|c|c|c|}
\hline Variáveis & IES & Média & $\begin{array}{l}\text { Desvio } \\
\text { Padrão }\end{array}$ & $\begin{array}{l}p \text {-valor } \\
\text { Levene }\end{array}$ & $\begin{array}{l}\mathrm{p} \text {-valor } \\
\text { teste- } t\end{array}$ \\
\hline \multirow{2}{*}{$\begin{array}{l}\text { Espera da determinação do que aprender } \\
\text { e como aprender }\end{array}$} & Pública & 3,62 & 0,74 & \multirow[t]{2}{*}{0,05} & \multirow[t]{2}{*}{0,13} \\
\hline & Privada & 3,84 & 0,99 & & \\
\hline \multirow[t]{2}{*}{ Iniciativa no processo de aprendizagem. } & Pública & 3,28 & 0,91 & \multirow[t]{2}{*}{0,36} & \multirow[t]{2}{*}{$0,00 *$} \\
\hline & Privada & 3,78 & 0,82 & & \\
\hline \multirow{2}{*}{$\begin{array}{l}\text { Capacidade de evoluir e agir de maneira } \\
\text { autônoma }\end{array}$} & Pública & 3,55 & 1,02 & \multirow[t]{2}{*}{0,29} & \multirow[t]{2}{*}{$0,02 *$} \\
\hline & Privada & 3,96 & 1,05 & & \\
\hline \multirow{2}{*}{$\begin{array}{l}\text { Independência no processo de } \\
\text { aprendizagem. }\end{array}$} & Pública & 3,41 & 0,94 & \multirow[t]{2}{*}{0,97} & \multirow[t]{2}{*}{$0,02^{*}$} \\
\hline & Privada & 3,80 & 0,99 & & \\
\hline \multirow{2}{*}{$\begin{array}{l}\text { Responsabilidade pela própria } \\
\text { aprendizagem }\end{array}$} & Pública & 3,72 & 0,96 & \multirow[t]{2}{*}{0,61} & \multirow[t]{2}{*}{$0,00^{*}$} \\
\hline & Privada & 4,16 & 1,03 & & \\
\hline \multirow[t]{2}{*}{ Programação dos próprios estudos. } & Pública & 3,05 & 1,19 & \multirow[t]{2}{*}{0,11} & \multirow[t]{2}{*}{$0,04^{*}$} \\
\hline & Privada & 3,43 & 0,95 & & \\
\hline \multirow{2}{*}{$\begin{array}{l}\text { Habilidade para solucionar os problemas } \\
\text { existentes no seu processo de } \\
\text { aprendizagem. }\end{array}$} & Pública & 3,38 & 0,99 & \multirow[t]{2}{*}{0,89} & \multirow[t]{2}{*}{0,15} \\
\hline & Privada & 3,61 & 0,96 & & \\
\hline \multirow{2}{*}{$\begin{array}{l}\text { Comprometimento com a própria } \\
\text { aprendizagem. }\end{array}$} & Pública & 3,68 & 0,95 & \multirow[t]{2}{*}{0,48} & \multirow[t]{2}{*}{0,75} \\
\hline & Privada & 3,73 & 1,09 & & \\
\hline
\end{tabular}

* A diferença de média é significativa ao nível 0,05.

Tabela 7 - teste- $t$ para amostras independentes - o conceito de si Fonte: Dados da pesquisa (2019). 
Os dados da Tabela 7 mostram, por meio do teste- $t$ de amostras independentes, a diferença entre as médias da IES pública e privada nas variáveis "Iniciativa no processo de aprendizagem", "Capacidade de evoluir e agir de maneira autônoma", "Independência no processo de aprendizagem", "Responsabilidade pela própria aprendizagem" e "Programação dos próprios estudos".

Isso evidencia que os acadêmicos da universidade privada, em comparação aos acadêmicos da universidade pública, destoam com maior iniciativa no seu processo de aprendizagem, têm maior capacidade de evoluir de maneira autônoma, possuem maior independência no processo, são mais responsáveis por essa aprendizagem e possuem maior programação dos próprios estudos.

\section{Prontidão para aprender}

Neste quesito, analisou-se a necessidade de suporte e de direção. Knowles, Holton e Swanson (2011) relatam que o termo direção trata da necessidade de assistência por outra pessoa no processo de aprendizagem e suporte faz referência ao apoio afetivo que ela espera receber dos outros. Na Tabela 8 , apresentam-se os dados relacionados à prontidão em aprender.

\begin{tabular}{l|c|c|c|c|c|c}
\hline & \multicolumn{3}{|c|}{ IES Pública } & \multicolumn{3}{c}{ IES Privada } \\
\hline & CB & CM & CA & CB & CM & CA \\
\hline Necessidade de suporte (apoio afetivo de terceiros) & 17 & 27 & $\underline{\mathbf{3 0}}$ & 20 & 26 & $\underline{\mathbf{2 8}}$ \\
\hline Necessidade de direção & 10 & 31 & $\underline{\mathbf{3 3}}$ & 20 & 23 & $\underline{\mathbf{3 0}}$ \\
\hline
\end{tabular}

Tabela 8 - Prontidão para aprender

Fonte: Dados da pesquisa (2019).

Os resultados denotam que os acadêmicos do curso de Ciências Contábeis, sejam da IES pública ou privada, precisam, em sua maioria, de suporte e direção no processo de aprendizagem. Esse mesmo resultado também é observado no estudo de Brandão, Cavalcante e Temoteo (2014), no qual se percebe que os acadêmicos de Turismo e Hotelaria apresentam, em sua maioria, a necessidade de suporte. Isso reflete que, embora se espera que o ensino superior seja autodirigido, é necessário o suporte para que esse aluno permaneça no curso e tenha vontade de aprender. De forma a confirmar esses resultados, a diferença das médias apresenta-se na Tabela 9. 
Aprendizagem à luz da Andragogia: comparação da percepção de discentes entre cursos de Ciências Contábeis

Kelly Renata Mariani Kozievitch, Lucas Précoma Lorenzini, Moacir Borges da Silva, Silvana Anita Walter

\begin{tabular}{l|c|c|c|c|c}
\hline Variáveis & IES & Média & $\begin{array}{c}\text { Desvio } \\
\text { Padrão }\end{array}$ & $\begin{array}{c}p \text {-valor } \\
\text { Levene }\end{array}$ & $\begin{array}{c}p \text {-valor } \\
\text { teste- } t\end{array}$ \\
\hline Necessidade de suporte (apoio afetivo de & Pública & 3,24 & 1,02 & 0,27 & 0,56 \\
\cline { 2 - 4 } \begin{tabular}{l} 
terceiros) \\
\cline { 1 - 4 } Necessidade de direção
\end{tabular} & Privada & 3,14 & 1,21 & & \\
\cline { 2 - 4 } & Pública & 3,46 & 0,91 & 0,13 & $0,01^{*}$ \\
\cline { 2 - 4 } & Privada & 3,01 & 1,21 & & \\
\hline
\end{tabular}

* A diferença de média é significativa ao nível 0,05.

Tabela 9 - Teste-t para amostras independentes - prontidão para aprender Fonte: Dados da pesquisa (2019).

O teste- $t$ mostrou uma diferença significativa nas médias da variável "Necessidade de direção", tendo o aluno da IES pública maior necessidade de direção que o aluno da IES privada.

\section{Orientação para aprendizagem}

Rogers e Freiberg (1969) afirmam que a aprendizagem é significativa quando o aluno percebe a relevância do que será aprendido, quando de fato ele visualiza a sua utilidade. Nesse bloco, foi questionado sobre a utilidade da aprendizagem desse acadêmico quanto à resolução de problemas, à execução de uma tarefa e à aplicação em situações diárias.

\begin{tabular}{l|c|c|c|c|c|c}
\hline & \multicolumn{3}{|c|}{ IES Pública } & \multicolumn{3}{c}{ IES Privada } \\
\hline & CB & CM & CA & CB & CM & CA \\
\hline $\begin{array}{l}\text { A aprendizagem é significativa quando ajuda na } \\
\text { resolução de problemas. }\end{array}$ & 2 & 12 & 60 & 5 & 17 & 52 \\
\hline $\begin{array}{l}\text { A aprendizagem é significativa quando ajuda na } \\
\text { execução de uma tarefa. }\end{array}$ & 1 & 10 & $\underline{\mathbf{6 3}}$ & 5 & 12 & $\underline{\mathbf{5 7}}$ \\
\hline $\begin{array}{l}\text { A aprendizagem é significativa quando se aplica nas } \\
\text { situações diárias. }\end{array}$ & 1 & 10 & $\underline{\mathbf{6 3}}$ & 2 & 21 & 51 \\
\hline
\end{tabular}

Tabela 10 - Orientação para aprendizagem

Fonte: Dados da pesquisa (2019).

Os resultados encontrados enfatizam que a concordância é alta nas três utilidades pesquisadas. No entanto, dentre as três, a execução de uma tarefa ainda se sobressai apresentando a maior concordância, o que pode ser explicado pelo fato de o curso de Ciências Contábeis ser um curso normativo por essência, vez que os procedimentos contábeis são geralmente ensinados com a prática das tarefas, ainda que amparados por normas específicas. 
Aprendizagem à luz da Andragogia: comparação da percepção de discentes entre cursos de Ciências Contábeis

Kelly Renata Mariani Kozievitch, Lucas Précoma Lorenzini, Moacir Borges da Silva, Silvana Anita Walter

\begin{tabular}{|c|c|c|c|c|c|}
\hline Variáveis & IES & Média & $\begin{array}{l}\text { Desvio } \\
\text { Padrão }\end{array}$ & $\begin{array}{l}p \text {-valor } \\
\text { Levene }\end{array}$ & $\begin{array}{l}p \text {-valor } \\
\text { teste-t }\end{array}$ \\
\hline \multirow{2}{*}{$\begin{array}{l}\text { A aprendizagem é significativa quando } \\
\text { ajuda na resolução de problemas. }\end{array}$} & Pública & 4,22 & 0,82 & \multirow[t]{2}{*}{0,66} & \multirow[t]{2}{*}{$0,05^{*}$} \\
\hline & Privada & 3,93 & 0,94 & & \\
\hline \multirow{2}{*}{$\begin{array}{l}\text { A aprendizagem é significativa quando } \\
\text { ajuda na execução de uma tarefa. }\end{array}$} & Pública & 4,27 & 0,75 & \multirow[t]{2}{*}{0,85} & \multirow[t]{2}{*}{$0,05 *$} \\
\hline & Privada & 4,00 & 0,97 & & \\
\hline \multirow{2}{*}{$\begin{array}{l}\text { A aprendizagem é significativa quando se } \\
\text { aplica nas situações diárias. }\end{array}$} & Pública & 4,36 & 0,77 & \multirow[t]{2}{*}{0,48} & \multirow[t]{2}{*}{$0,01^{*}$} \\
\hline & Privada & 3,96 & 0,99 & & \\
\hline
\end{tabular}

* A diferença de média é significativa ao nível 0,05.

Tabela 11 - Teste-t para amostras independentes - orientação para aprendizagem Fonte: Dados da pesquisa (2019).

Ao aplicar o teste-t, esse retornou diferença significativa entre as médias nas três variáveis. Neste constructo, os acadêmicos da IES pública obtêm maior média de concordância nas três variáveis. No caso, é possível afirmar que esses acadêmicos mostram dar significado ao que se aprende, relacionando a aprendizagem com resolução de problemas, execução de uma tarefa e em aplicabilidade em situações diárias.

\section{Motivação para aprender}

De acordo com Kolb (1984), cada indivíduo possui um "reservatório de experiências" ou "loja de lembranças na mente" e, quando este acredita ser insuficiente para solucionar problemas diários, ou até mesmo situações complexas, ele desenvolve a necessidade de aprender para que possa colocar esse aprendizado em prática.

\begin{tabular}{l|c|c|c|c|c|c}
\hline \multicolumn{1}{c|}{ Variáveis } & \multicolumn{3}{c|}{ IES Pública } & \multicolumn{3}{c}{ IES Privada } \\
\cline { 2 - 9 } & CB & CM & CA & CB & CM & CA \\
\hline $\begin{array}{l}\text { Motivação quando acredita que a aprendizagem do } \\
\text { conteúdo o ajudará a resolver problemas. }\end{array}$ & 1 & 7 & $\underline{66}$ & 2 & 15 & 57 \\
\hline $\begin{array}{l}\text { Motivação associada à percepção da importância da } \\
\text { aprendizagem para sua vida. }\end{array}$ & 1 & 7 & $\underline{66}$ & 3 & 15 & 56 \\
\hline $\begin{array}{l}\text { Motivação associada ao reconhecimento da } \\
\text { importância do conteúdo que aprende. }\end{array}$ & 2 & 21 & 51 & 3 & 13 & $\underline{\mathbf{5 8}}$ \\
\hline $\begin{array}{l}\text { Motivação quando o processo de aprendizagem } \\
\text { possibilita uma experiência prazerosa. }\end{array}$ & 3 & 16 & 55 & 2 & 9 & $\underline{\mathbf{6 3}}$ \\
\hline
\end{tabular}

Tabela 12 - Motivação para aprender

Fonte: Dados da pesquisa (2019).

O acadêmico da IES pública tem como motivação mais evidente a que o conteúdo o ajudará a resolver problemas e será importante para sua vida pessoal, já o acadêmico da IES privada tem como motivação mais evidente a importância do que aprende e a experiência prazerosa que a aprendizagem proporciona. 
Logo, embora se tenha alguns respondentes de concordância baixa no que concerne aos aspectos motivacionais para aprendizagem, os resultados corroboram com o esperado na abordagem andragógica, contribuindo positivamente para um aprendizado mais autodirecionado.

\begin{tabular}{|c|c|c|c|c|c|}
\hline Variáveis & IES & Média & $\begin{array}{l}\text { Desvio } \\
\text { Padrão }\end{array}$ & $\begin{array}{l}p \text {-valor } \\
\text { Levene }\end{array}$ & $p$-valor teste- $t$ \\
\hline \multirow{2}{*}{$\begin{array}{l}\text { Motivação quando acredita que a } \\
\text { aprendizagem do conteúdo o ajudará a } \\
\text { resolver problemas. }\end{array}$} & Pública & 4,42 & 0,72 & \multirow[t]{2}{*}{0,18} & \multirow[t]{2}{*}{$0,05^{*}$} \\
\hline & Privada & 4,16 & 0,89 & & \\
\hline \multirow{2}{*}{$\begin{array}{l}\text { Motivação associada à percepção da } \\
\text { importância da aprendizagem para sua } \\
\text { vida. }\end{array}$} & Pública & 4,38 & 0,72 & \multirow[t]{2}{*}{0,38} & \multirow[t]{2}{*}{$0,03 *$} \\
\hline & Privada & 4,09 & 0,86 & & \\
\hline \multirow{2}{*}{$\begin{array}{l}\text { Motivação associada ao reconhecimento } \\
\text { da importância do conteúdo que aprende. }\end{array}$} & Pública & 4,04 & 0,88 & \multirow[t]{2}{*}{0,16} & \multirow[t]{2}{*}{0,85} \\
\hline & Privada & 4,07 & 0,82 & & \\
\hline \multirow{2}{*}{$\begin{array}{l}\text { Motivação quando o processo de } \\
\text { aprendizagem possibilita uma experiência } \\
\text { prazerosa. }\end{array}$} & Pública & 4,24 & 0,98 & \multirow[t]{2}{*}{0,01} & \multirow[t]{2}{*}{0,85} \\
\hline & Privada & 4,27 & 0,78 & & \\
\hline
\end{tabular}

* A diferença de média é significativa ao nível 0,05.

Tabela 13 - Teste-t para amostras independentes - motivação para aprender Fonte: Dados da pesquisa (2019).

Tratando da diferença de médias entre os acadêmicos das duas IES, as variáveis que resultaram em uma diferença significativa foram a "Motivação quando acredita que a aprendizagem do conteúdo o ajudará a resolver problemas" e a "Motivação associada à percepção da importância da aprendizagem para sua vida". Pelas médias encontradas, podese evidenciar que o acadêmico da IES pública tem maior motivação quando acredita que aprender o conteúdo ajudará a resolver problemas e tem maior percepção da importância da aprendizagem na sua vida.

\section{Resumo de diferenças encontradas}

Relatadas as diferenças de médias por dimensão em cada atributo da Andragogia, a Tabela 14 evidencia os resultados que obtiveram diferenças de médias significativas nas variáveis. 
Aprendizagem à luz da Andragogia: comparação da percepção de discentes entre cursos de Ciências Contábeis

Kelly Renata Mariani Kozievitch, Lucas Précoma Lorenzini, Moacir Borges da Silva, Silvana Anita Walter

\begin{tabular}{|c|c|c|c|c|c|}
\hline Variáveis & IES & Média & GAP & $\begin{array}{c}\text { GAP } \\
\text { atributo }\end{array}$ & $p$-valor teste- $t$ \\
\hline \multirow[t]{2}{*}{ Iniciativa no processo de aprendizagem. } & Pública & 3,28 & \multirow{2}{*}{-} & \multirow{10}{*}{$-2,12$} & $0,00^{*}$ \\
\hline & Privada & 3,78 & & & \\
\hline \multirow{2}{*}{$\begin{array}{l}\text { Capacidade de evoluir e agir de maneira } \\
\text { autônoma }\end{array}$} & Pública & 3,55 & \multirow{2}{*}{-} & & \multirow[t]{2}{*}{$0,02^{*}$} \\
\hline & Privada & 3,96 & & & \\
\hline \multirow{2}{*}{$\begin{array}{l}\text { Independência no processo de } \\
\text { aprendizagem. }\end{array}$} & Pública & 3,41 & \multirow{2}{*}{$\begin{array}{c}- \\
0,39\end{array}$} & & \multirow[t]{2}{*}{$0,02 *$} \\
\hline & Privada & 3,80 & & & \\
\hline \multirow{2}{*}{$\begin{array}{l}\text { Responsabilidade pela própria } \\
\text { aprendizagem }\end{array}$} & Pública & 3,72 & \multirow{2}{*}{ 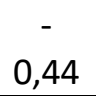 } & & \multirow[t]{2}{*}{$0,00^{*}$} \\
\hline & Privada & 4,16 & & & \\
\hline \multirow[t]{2}{*}{ Programação dos próprios estudos. } & Pública & 3,05 & \multirow{2}{*}{$\begin{array}{c}- \\
0,38\end{array}$} & & \multirow[t]{2}{*}{$0,04^{*}$} \\
\hline & Privada & 3,43 & & & \\
\hline \multirow[t]{2}{*}{ Necessidade de direção } & Pública & 3,46 & \multirow{2}{*}{0,45} & \multirow{2}{*}{0,45} & $0,01 *$ \\
\hline & Privada & 3,01 & & & \\
\hline \multirow{2}{*}{$\begin{array}{l}\text { A aprendizagem é significativa quando } \\
\text { ajuda na resolução de problemas. }\end{array}$} & Pública & 4,22 & \multirow{2}{*}{0,29} & \multirow{6}{*}{0,96} & \multirow[t]{2}{*}{$0,05^{*}$} \\
\hline & Privada & 3,93 & & & \\
\hline \multirow{2}{*}{$\begin{array}{l}\text { A aprendizagem é significativa quando } \\
\text { ajuda na execução de uma tarefa. }\end{array}$} & Pública & 4,27 & \multirow{2}{*}{0,27} & & \multirow[t]{2}{*}{$0,05^{*}$} \\
\hline & Privada & 4,00 & & & \\
\hline \multirow{2}{*}{$\begin{array}{l}\text { A aprendizagem é significativa quando se } \\
\text { aplica nas situações diárias. }\end{array}$} & Pública & 4,36 & \multirow{2}{*}{0,40} & & $0,01 *$ \\
\hline & Privada & 3,96 & & & \\
\hline \multirow{2}{*}{$\begin{array}{l}\text { Motivação quando acredita que a } \\
\text { aprendizagem do conteúdo o ajudará a } \\
\text { resolver problemas. }\end{array}$} & Pública & 4,42 & \multirow[b]{2}{*}{0,26} & \multirow{4}{*}{0,55} & \multirow[t]{2}{*}{$0,05^{*}$} \\
\hline & Privada & 4,16 & & & \\
\hline \multirow{2}{*}{$\begin{array}{l}\text { Motivação associada à percepção da } \\
\text { importância da aprendizagem para sua } \\
\text { vida. }\end{array}$} & Pública & 4,38 & \multirow[b]{2}{*}{0,29} & & $0,03 *$ \\
\hline & Privada & 4,09 & & & \\
\hline
\end{tabular}

* A diferença de média é significativa ao nível 0,05.

Tabela 14 - Diferenças de médias significativas nas variáveis Fonte: Dados da pesquisa (2019).

$\mathrm{Na}$ abordagem do conceito de si, apresentou-se um GAP total de -2,12 da IES pública para a IES privada, ou seja, os acadêmicos da IES privada possuem maior iniciativa e independência no seu processo de aprendizagem, autonomia e responsabilidade pela própria aprendizagem além de ter uma maior programação dos próprios estudos, quando comparados aos acadêmicos de IES pública.

Essa diferença significativa corrobora com a variável "Necessidade de direção", apresentando um GAP de 0,45, o qual evidencia que o acadêmico da IES pública é mais dependente de que alguém lhe forneça a direção dos seus estudos. Quanto à orientação para aprendizagem, o GAP foi de 0,96. Logo, o entendimento é que esses mesmos acadêmicos entendem que a aprendizagem é mais significativa quando ajuda na resolução de problemas, na execução de uma tarefa ou ainda quando se aplica nas situações diárias. 
Quanto à motivação para aprender, o GAP foi de 0,55 . Suas diferenças são significativas pelo fato de que o acadêmico da IES pública acredita que aprender o conteúdo o ajudará a resolver problemas e por entender que a aprendizagem é importante para sua vida, tendo maior motivação nesses quesitos do que o acadêmico da IES privada.

\section{CONSIDERAÇÕES FINAIS}

Este estudo analisou a percepção dos alunos do curso de Ciências Contábeis quanto ao seu processo de aprendizagem por meio do modelo desenvolvido por Knowles, Holton e Swanson (2011). A pesquisa foi realizada em duas instituições de ensino superior, sendo uma entidade pública e a outra da iniciativa privada. As informações foram analisadas e comparadas, tendo em vista que em estudos anteriores o modelo foi aplicado apenas em um curso específico de determinada instituição de ensino.

As afirmações da pesquisa estavam vinculadas aos seis princípios da Andragogia e foram evidenciadas por blocos a fim de realizar a comparabilidade dos respondentes, conforme a sua IES. Os resultados denotam poucas diferenças entre os acadêmicos das IES quanto à aprendizagem.

No primeiro princípio, os estudantes possuem, na maioria, alta compreensão da necessidade de aprender. Porém, 31 respondentes da IES pública concordaram de forma moderada quanto à compreensão de como a aprendizagem é conduzida, evidenciando dúvidas quanto aos métodos utilizados para transmissão dos conteúdos e não denotando diferença significativa nas médias pelo teste-t.

No segundo princípio, os resultados evidenciam certa dependência do aluno na espera da determinação do que aprender e em como aprender. Ainda que a maioria dos respondentes se considerem independentes e responsáveis pelo seu processo de aprendizagem, denota-se uma dependência do discente em $62 \%$ na IES privada e $52 \%$ na IES pública, o que, por consequência, influencia na programação dos próprios estudos, pois $64 \%$ dos respondentes da instituição pública e $58 \%$ dos respondentes da instituição privada apresentaram concordância baixa a moderada nessa afirmação. Ao tratar da experiência prévia do acadêmico, o terceiro princípio foi excluído por apresentar um Alpha de Cronbach de 0,345, considerado inaceitável para continuação do estudo.

O objeto de avaliação do quarto princípio andragógico foi o emocional do discente. A necessidade de assistência de pessoa no processo de aprendizagem e a de suporte afetivo que ele espera receber são responsáveis por sua prontidão para aprender. Ambos respondentes 
apresentaram concordância alta nessa afirmação, indicando a necessidade de apoio de outra pessoa para incentivar sua aprendizagem.

A utilidade do que se está aprendendo foi o objeto do quinto princípio andragógico. Esse demonstrou que a amostra em sua maioria dá significado à aprendizagem quando esta ajuda na execução de uma tarefa ou ainda quando esta se aplica a situações diárias, o que pode ser explicado pelo caráter normativo do curso, já que o acadêmico que escolhe esse curso busca na universidade o entendimento das normas e legislações impostas para exercício da sua atividade. Essa ponderação foi mais bem evidenciada em acadêmicos da IES pública e apresentou significância ao nível de 0,05 no teste-t.

Por fim, no sexto princípio andragógico, foram analisadas as motivações dos acadêmicos para aprender. Neste ponto, os acadêmicos das diferentes instituições divergem e apresentam em sua maioria concordância alta em pontos diferentes. Para o acadêmico da IES pública, que obteve diferença de média significativa no teste-t, aprender o conteúdo ajuda a resolver problemas e será importante para sua vida pessoal, e isso o motiva a aprender, enquanto para o acadêmico da IES privada a motivação está diretamente ligada à importância do conteúdo e a experiência prazerosa que a aprendizagem proporciona.

Os fundamentos da Andragogia direcionam a responsabilidade e o compromisso da aprendizagem para o estudante. Porém, observa-se, pelos resultados das análises, que os acadêmicos respondentes, tanto de IES pública quanto de privada, estão em processo de entendimento dessa condição de estudante adulto, ainda possuem dependência do docente, precisam de incentivos de terceiros e têm dificuldades em resolver seus problemas de aprendizagem.

Por outro lado, por mais simples e pequena que seja, existe a evidência de que esses acadêmicos estão em busca desse caminho da aprendizagem andragógica: ao identificar os motivos para aprendizagem em uma experiência prazerosa; ao apontar a utilidade da aprendizagem para resolver situações diárias; ao afirmar que a aprendizagem se torna mais fácil utilizando sua experiência prévia; e, por fim, ao possuir comprometimento com sua própria aprendizagem. Tais apontamentos demonstram, mesmo que timidamente, a vontade de desprender-se do modelo de aprendizagem pedagógico.

Esta pesquisa não pretendeu esgotar o tema estudado, e novos estudos podem ser propostos com o incremento de outras variáveis, como a avaliação da estrutura acadêmica, a avaliação dos docentes e a avaliação do currículo, a fim de demonstrar a influência dessas no formato de aprendizagem do acadêmico. 


\section{REFERÊNCIAS}

BELLAN, Zezina. Andragogia em ação: como ensinar adultos sem ser maçante. São Paulo: Câmara Brasileira do Livro, 2005.

BRANDÃO, Jammilly Mikaela Fagundes; CAVALCANTE, Erica Dayane Chaves; TEMOTEO, Joelma Abrantes Guedes. O Processo de Aprendizagem de Alunos de Turismo e Hotelaria Sob a Perspectiva Andragógica. Revista Brasileira de Pesquisa em Turismo, São Paulo, v. 8, n. 3, p. 531-551, 2014. DOI: http://dx.doi.org/10.7784/rbtur.v8i3.802.

CARVALHO, José Ricardo. Andragogia: saberes docentes na educação de adultos. Revista Diálogos Acadêmicos, Fortaleza, v. 5, n. 2, p. 79-85, 2017.

CORTINA, Jose M. What is coefficient alpha? An examination of theory and applications. Journal of applied psychology, Washington, v. 78, n. 1, p. 98, 1993. DOI: https://doi.org/10.1037/0021-9010.78.1.98.

COSTA, Patrícia de Souza; GOMES, Gilvania de Souza; BRAUNBECK, Guillermo O.; SANTANA, Maria Eduarda Gomes. Um safari no Brasil: evidências sobre o ensino baseado na estrutura conceitual. Revista Contabilidade \& Finanças, São Paulo, v. 9, n. 76, p. 129-147, 2018. DOI: https://doi.org/10.1590/1808-057x201804760.

EBOLI, Marisa. O papel das lideranças no êxito de um sistema de educação corporativa. Revista de Administração de Empresas, São Paulo, v. 45, n. 4, p. 118-122, 2005.

FRANCO, David Silva; PAIVA, Kely Cesar Martins de; HELMOLD, Stefânia de Castro. Possibilidades e desafios para uma abordagem andragógica no ensino em Administração e Contabilidade. Revista ADM.MADE, Rio de Janeiro, v. 19 n. 3, p. 16-33, 2015.

GODOI, Alexandre Franco; FERREIRA, Jeferson Vinhas. Metodologia ativa de aprendizagem para o ensino em administração: relatos da experiência com a aplicação do peer instruction em uma instituição de ensino superior. Revista Eletrônica de Administração, Franca, v. 15, n. 2, p. 337-352, 2016.

HAIR JR., Joseph F.; BABIN, Barry; MONEY, Arthur H.; SAMOUEL, Phillip.

(2007). Fundamentos de métodos de pesquisa em administração. [S.I.]: Bookman Companhia, 2005.

KNOWLES, Malcolm S.; HOLTON, Elwood F.; SWANSON, Richard A. The adult learner: The definitive classic in adult education and human resource development. Londres: Elsevier, 2011.

KNOWLES, Malcolm S. The modern practice of adult education: from pedagogy to andragogy. Westchester: Follett Pub. Co, 1980. 
Aprendizagem à luz da Andragogia: comparação da percepção de discentes entre cursos de Ciências Contábeis

Kelly Renata Mariani Kozievitch, Lucas Précoma Lorenzini, Moacir Borges da Silva, Silvana Anita Walter

KOLB, David A. Experiential learning. Englewood Cliffs: Prentice Hall, 1984.

ROGERS, Carl R.; FREIBERG, H. Jerome. Freedom to learn. Columbus: Charles E. Merrill Pub, 1969.

ROMANZI, Junior Vitório; VIDI Franciele. Andragogia: um caminho didático no ensino superior. Revista Conversatio, Florianópolis, v. 2, n. 4, p. 258-273, 2017.

SCHLOCHAUER, Conrado; LEME, Maria Isabel da Silva. Aprendizagem ao longo da vida: uma condição fundamental para a carreira. Revista de Carreiras e Pessoas, São Paulo, v. 2, n. 2, 2012. DOI: https://doi.org/10.20503/recape.v2i2.11864.

SCHMIDT, Paulo; OTT, Ernani; SANTOS, José Luis dos; FERNANDES, Andreia Castiglia. Perfil dos alunos do curso de Ciências Contábeis de Instituições de Ensino do Sul do Brasil. ConTexto - Revista do Programa de Pós-Graduação em Controladoria e Contabilidade da UFRGS, Porto Alegre, v. 12, n. 21, 2012.

SILVA, Maria Luiza de Carvalho Araújo da; TORRES, Milton Luiz. O estado da arte em Andragogia: uma análise nas produções científicas. Acta Científica, Engenheiro Coelho, v. 26, n. 2, p. 43-54, 2017. DOI: https://doi.org/10.19141/2236-2622.actacientifica.v26.n2.p43-54. 


\section{Kelly Renata Mariani Kozievitch}

Mestranda em Contabilidade pela Universidade do Oeste do Paraná - Unioeste. Especialista em Auditoria e Perícia Contábil. Professora universitária das disciplinas de Contabilidade Pública, Atuarial e Prática Profissional no Centro Universitário Dinâmica das Cataratas - UDC em Foz do Iguaçu - PR.

kellyrenata@udc.edu.br

\section{Lucas Précoma Lorenzini}

Mestrando em contabilidade pela Universidade do Oeste do Paraná - Unioeste, campi Cascavel, Gestor de Custos e Planejamento estratégico orçamentário e professor universitário nas disciplinas de Gestão de Custos, Contabilidade e Auditoria e Perícia.

Iplorenzini@gmail.com

\section{Moacir Borges da Silva}

Graduação em Ciências Contábeis pela Universidade Estadual do Oeste do Paraná, Unioeste Brasil, 1985; Especialização em Auditoria e Gerência Financeira pela Universidade Estadual do Oeste do Paraná - Unioeste, Título: Gerência do Capital de Giro. Orientador: Edison Luiz Leismann,1999; Graduação em Direito pela União Educacional de Cascavel, UNIVEL, Brasil, Título: Substituição Tributária. Orientador: Charles R Resin. 2003.

moacirbs62@gmail.com

\section{Silvana Anita Walter}

Doutora em Administração pela PUCPR. Professora da Universidade Estadual do Oeste do Paraná. Leciona no Programa de Pós-Graduação em Contabilidade e na Graduação em Administração. Leciona disciplinas de Técnicas relacionadas à Pesquisa e Metodologia da Pesquisa Qualitativa. Estuda preferencialmente o Ensino e a Pesquisa em Administração e Contabilidade (teorias, metodologias de ensino e pesquisa). É bolsista produtividade em pesquisa. Universidade Estadual do Oeste do Paraná (Unioeste). Campus de Marechal Cândido Rondon.

silvanaanita.walter@gmail.com 